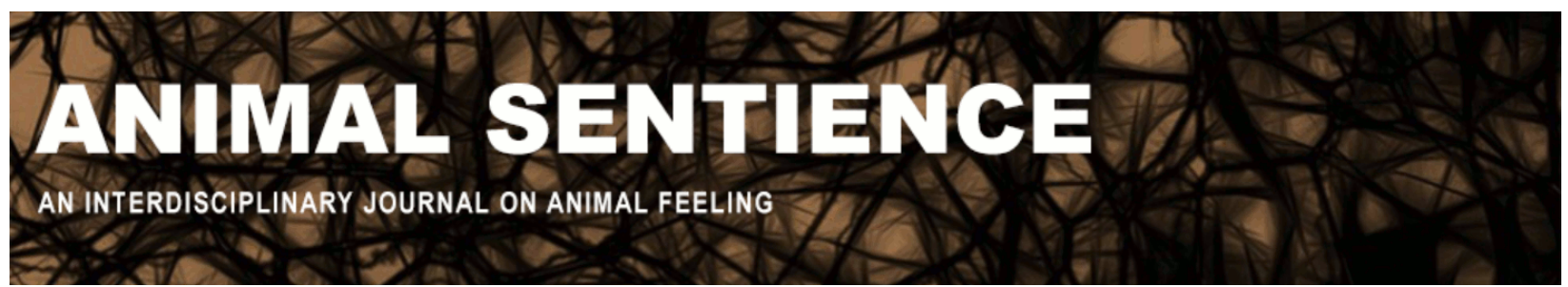

Correia-Caeiro, Catia (2020) Rewilding and domestication: Clarifying terminology. Animal Sentience 28(17)

DOI: $10.51291 / 2377-7478.1577$

Date of submission: $2020-04-17$

Date of acceptance: $2020-04-24$

(c)

This article has appeared in the journal Animal

Sentience, a peer-reviewed journal on animal

cognition and feeling. It has been made open access,

free for all, by WellBeing International and deposited

in the WBI Studies Repository. For more information,

please contact

wbisr-info@wellbeingintl.org.

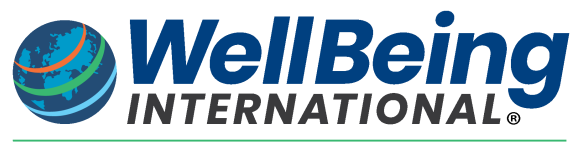

SOLUTIONS FOR PEOPLE, ANIMALS AND ENVIRONMENT 


\title{
Rewilding and domestication: Clarifying terminology
}

Commentary on Baker \& Winkler on Elephant Rewilding

\section{Catia Correia-Caeiro}

Primate Research Institute, Kyoto University

\begin{abstract}
Baker \& Winkler (B\&W) describe the state of Asian elephant conservation, raising unique issues, and proposing a direction based on rewilding. The long history and socio-biology of elephants and humans has some parallels with the domestication of dogs (and other species). However, markers of domestication seem absent from elephants. The proper use of terms such as "wild" and "domestic" is crucial in defining the best conservation strategies, and, more important, in attending to the welfare needs of individuals, which can differ between wild and domestic animals. B\&W's target article represents an important starting point for discussion around elephant conservation, but concepts need to be clarified.
\end{abstract}

Catia Correia-Caeiro studies cognitive capacities in different species (e.g., primates and domestic animals) from comparative and evolutionary perspectives. Her research focuses on communication and emotional processes in nonhuman animals. Website

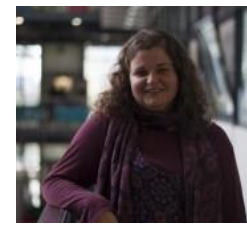

1. Being wild. Mehrkam \& Fad's (2020) commentary has pointed out the oxymoron of conflating "wild" and "intensively managed." Acknowledging that an elephant population is not wild does not make conservation efforts and the improvement of the human-elephant relationship any less valuable, but to confuse intensively managed individuals with wild ones is to devalue the conservation efforts devoted to keeping those species (and others) in the wild. Wild individuals should not be seen as "better" than captive/managed individuals, but appropriate categorisation will help identify specific individual needs that may differ between managed, captive and wild. New categories of wild/managed animals might be needed for best conservation practices. Even though there is an exponential growth of human population around the world, Thailand's human population is projected to decrease (United Nations, 2020), which brings hope to conservationists. In this scenario, Blumstein \& Lynch's (2020) suggestion of balancing elephant numbers between ecotourism and keeping others wild might work well. Pauketat (2020) mentions elephant-human interdependence, but judging by Baker \& Winkler's (2020) (B\&W) article, this is largely a unilateral dependence: humans need elephants but elephants only need humans to protect them from other humans.

2. Being domesticated. There is some confusion in both the target article and several commentaries (e.g., Lorimer \& Rahmat 2020) on the definition of domestication. This confusion is common in the elephant conservation literature (e.g., Laohachaiboon 2010, where "domestication," "tame" and "owned" are used interchangeably). Although some 
populations/species might fall in a grey area in terms of degree of domestication (Russell 2002), we have extensive information on the domestication patterns and processes (Larson \& Fuller 2014, Diamond 2002). The appropriate use of domestication has profound implications for human-animal relations. It is generally agreed that domesticates differ from their wild ancestors genetically (Frantz et al. 2020), behaviourally (Wheat et al. 2019) and morphologically (O'Regan et al. 2005). Characteristics of domesticated animals include tamability, loss of reproductive seasonality (usually controlled by humans), dependence on humans for feeding, and changes in coat colour, ear form, tail form and craniofacial morphology (Diamond 2002, Lord et al. 2020). None of these seem to have been identified in managed/captive Asian elephants.

This confusion seems to arise from elephants' thousands of years of work alongside humans, similar to the case of dogs. There are no reports of artificial selection for specific traits in elephants (Plotnik et al. 2013, Lair 1997); so they are probably genetically wild (Plotnik et al. 2013, Nozawa \& Shotake 2009). Taming wild individuals is distinct from genetic domestication (Diamond 2002). Even with extensive exposure to humans from a young age, Asian elephants do not show behavioural markers of domestication, which are very clear in dogs (Hare et al. 2002) and other domesticated species (e.g., cats: Bradshaw 2012, horses: Yarnell 2015). Dogs (like other domestic species) show specific cognitive skills that are a product of domestication, such as using human social cues (Kaminski \& Nitzschner 2013) or processing human facial expressions (Somppi et al. 2016, Correia-Caeiro et al. 2020). The absence of these abilities in elephants (e.g., Plotnik et al. 2013) is not due to poor cognition, as Asian elephants are known to have complex social and visual cognitive skills (Payne 2003), such as mirror self-recognition (Plotnik et al. 2006) and the aptitude for cooperative work (Plotnik et al. 2011). It has been suggested that some species are very hard to domesticate due to their socio-ecology, which for the elephant might be related to a slow growth rate and long birth spacing (Diamond 2002).

$B \& W$ also seem to conflate domesticated with working animals. Historically, all domesticates provided a service to humans, but today many species (e.g., cats, most owned dogs, ferrets, etc.) perform no function for humans other than companionship.

3. Why wild vs. domestic matters. Since domestication is an evolutionary process of adaptation caused by humans (Lord et al. 2020), it is important to understand whether a species is indeed domesticated, as that would mean that the species was to some extent genetically adapted to living in a human environment - that it had gone through genetic, behavioural and morphological changes that made a human environment suitable for their survival, fitness and wellbeing. Since there is no evidence that the Asian elephant is thus domesticated, the human environment might not be suitable. This is very relevant for elephant welfare. African elephants intensively managed for ecotourism still show increased stress hormones when interacting with humans (Millspaugh et al. 2007). This is in stark contrast to domesticated animals that show opposite effects - lower heart rate, decreased cortisol and increased "feel-good" hormones such as oxytocin - when interacting closely with humans (Handlin 2011). Without humans, elephants would thrive, unlike dogs or cats, who depend on humans even for their psychological wellbeing (e.g., many dogs display separation related problems when away from their human carers, de Assis et al. 2020). Moreover, it is not only the dogs who have evolved to benefit from human interaction: humans also show behavioural (Waller et al. 2013) and physiological (Nagasawa et al. 2015) changes thought to stem from co-evolution with dogs (Nagasawa et al. 
2015) through domestication. Contrary to what Lorimer \& Rahmat (2020) suggest, no evidence of co-evolution has been found in elephants.

4. Further discussion needed. We need to know more about the current techniques used in the elephant-mahout relationship (mentioned also by Laine 2020, and Snijders 2020). What kinds of phajaan are there? (B\&W mention this term is applied broadly to define any training technique.) Have mahout "knowledge and skills" been documented in a systematic and scientific way? Do we actually know what they know and how that compares with good practice for individuals' wellbeing? Suter (2020) argues for education and training of mahouts, hinting at a lack of standardisation in practices. This information is crucial to be able to advocate a conservation strategy that focuses on the elephant-mahout relationship, particularly to avoid aversive practices such as the ones pointed out by Kopnina (2020) and Mehrkan \& Fad (2020).

\section{References}

Baker, L., \& Winkler, R. (2020). Asian elephant rescue, rehabilitation, and rewilding. Animal Sentience 28(1).

Blumstein, D. T., \& Lynch, K. E. (2020). Innovative, yes: But is it rewilding? Animal Sentience 28(8).

Bradshaw, J. W. (2012). The behaviour of the domestic cat. Cabi.

Correia-Caeiro, C., Guo, K., \& Mills, D. S. (2020). Perception of dynamic facial expressions of emotion between dogs and humans. Animal Cognition, 1-12.

de Assis, L. S., Matos, R., Pike, T. W., Burman, O. H., \& Mills, D. S. (2020). Developing diagnostic frameworks in veterinary behavioral medicine: Disambiguating separation related problems in dogs. Frontiers in Veterinary Science, 6, 499.

Diamond, J. (2002). Evolution, consequences and future of plant and animal domestication. Nature, 418(6898), 700-707.

Frantz, L. A., Bradley, D. G., Larson, G., \& Orlando, L. (2020). Animal domestication in the era of ancient genomics. Nature Reviews Genetics, 1-12.

Handlin, L., Hydbring-Sandberg, E., Nilsson, A., Ejdebäck, M., Jansson, A., \& Uvnäs-Moberg, K. (2011). Short-term interaction between dogs and their owners: Effects on oxytocin, cortisol, insulin and heart rate-an exploratory study. Anthrozoös, 24(3), 301-315.

Hare, B., Brown, M., Williamson, C., \& Tomasello, M. (2002). The domestication of social cognition in dogs. Science, 298(5598), 1634-1636.

Kaminski, J., \& Nitzschner, M. (2013). Do dogs get the point? A review of dog-human communication ability. Learning and Motivation, 44(4), 294-302.

Kopnina, H. (2020). Of elephants and men. Animal Sentience 28(2).

Lainé, N. (2020). Anthropology and conservation. Animal Sentience 28(5).

Lair, R. (1997). Gone astray: The care and management of the Asian elephant in domesticity. Food and Agriculture Organization of the United Nations.

Laohachaiboon, S. (2010). Conservation for whom? Elephant conservation and elephant conservationists in Thailand. Japanese Journal of Southeast Asian Studies, 48(1), 74-95.

Larson, G., \& Fuller, D. Q. (2014). The evolution of animal domestication. Annual Review of Ecology, Evolution, and Systematics, 45, 115-136. 
Lord, K. A., Larson, G., Coppinger, R. P., \& Karlsson, E. K. (2019). The history of farm foxes undermines the animal domestication syndrome. Trends in Ecology \& Evolution.

Lorimer, J., \& Rahmat, K. (2020). Elephants at work. Animal Sentience 28(7).

Mehrkam, L. R., \& Fad, O. (2020). Animal welfare science and "a life worth living" for wild and captive elephants. Animal Sentience 28(10).

Millspaugh, J. J., Burke, T., Van Dyk, G. U. S., Slotow, R. O. B., Washburn, B. E., \& Woods, R. J. (2007). Stress response of working African elephants to transportation and safari adventures. The Journal of Wildlife Management, 71(4), 1257-1260.

Nagasawa, M., Mitsui, S., En, S., Ohtani, N., Ohta, M., Sakuma, Y., Onaka, T., Mogi, K., \& Kikusui, T. (2015). Oxytocin-gaze positive loop and the coevolution of human-dog bonds. Science, 348(6232), 333-336.

Nozawa, K., \& Shotake, T. (1990). Genetic differentiation among local populations of Asian elephant. Journal of Zoological Systematics and Evolutionary Research, 28(1), 40-47.

O'Regan, H. J., \& Kitchener, A. C. (2005). The effects of captivity on the morphology of captive, domesticated and feral mammals. Mammal Review, 35(3-4), 215-230.

Pauketat, J. V. (2020). A psychological perspective on elephant rewilding. Animal Sentience 28(4).

Payne, K. (2003). Sources of social complexity in the three elephant species. In: de Waal, F. B. M. \& Tyack, P. L. (editors), Animal social complexity: Intelligence, culture, and individualized societies. Cambridge, MA: Harvard University Press. 57-85.

Plotnik, J. M., de Waal, F. B., \& Reiss, D. (2006). Self-recognition in an Asian elephant. PNAS, 103, 17053-17057.

Plotnik, J. M., Lair, R., Suphachoksahakun, W., \& de Waal, F. B. M. (2011). Elephants know when they need a helping trunk in a cooperative task. PNAS, 108, 5116-5121.

Plotnik, J. M., Pokorny, J. J., Keratimanochaya, T., Webb, C., Beronja, H. F., Hennessy, A., ... \& Melville, B. L. (2013). Visual cues given by humans are not sufficient for Asian elephants (Elephas maximus) to find hidden food. PLoS One, 8(4).

Russell, N. (2002). The wild side of animal domestication. Society \& Animals, 10(3), 285-302.

Snijders, L. (2020). Ecological and evolutionary dynamics of elephant rewilding. Animal Sentience 28(6).

Somppi, S., Törnqvist, H., Kujala, M. V., Hänninen, L., Krause, C. M., \& Vainio, O. (2016). Dogs evaluate threatening facial expressions by their biological validity-Evidence from gazing patterns. PLoS One, 11(1).

Suter, I. (2020). Rewilding or reviewing: Conservation and the elephant-based tourism industry. Animal Sentience 28(3).

United Nations. (2020). UNdata.

Waller, B. M., Peirce, K., Caeiro, C. C., Scheider, L., Burrows, A. M., McCune, S., \& Kaminski, J. (2013). Paedomorphic facial expressions give dogs a selective advantage. PLoS One, 8(12).

Wheat, C. H., Fitzpatrick, J. L., Rogell, B., \& Temrin, H. (2019). Behavioural correlations of the domestication syndrome are decoupled in modern dog breeds. Nature Communications, 10(1), $1-9$.

Yarnell, K., Hall, C., Royle, C., \& Walker, S. L. (2015). Domesticated horses differ in their behavioural and physiological responses to isolated and group housing. Physiology \& Behavior, 143, 51-57. 


\section{Call for Papers}

Special Issue of the Journal of Consciousness Studies

Plant Sentience: Theoretical and Empirical Issues

Guest Editors: Vicente Raja (Rotman Institute of Philosophy, Western University)

Miguel Segundo-Ortin (School of Liberal Arts, University of Wollongong)

In this special issue, we address the issue of plant sentience/consciousness from different disciplines that combine both theoretical and empirical perspectives. Some of the questions to be addressed in the special issue include the following:

- Plants exhibit interesting behaviors; does this entail that they are conscious to some extent?

- What are the requirements for a living organism to be conscious? Do plants meet these requirements?

- What does the possibility of plant sentience/consciousness entail for the study of the evolution of consciousness?

- Is it just a categorical mistake to attribute consciousness to plants?

- Can we talk about different levels or degrees of consciousness?

\section{How to submit?}

\section{Deadline: June 1 $\mathbf{1}^{\text {st }}, \mathbf{2 0 2 0}$}

Please submit your papers (max. 9000 words including footnotes, references, abstract, etc.) to vgalian@uwo.ca with subject "Paper Special Issue JCS".

For more information, including bibliography and more detailed descriptions of the topics and questions to be addressed in the papers submitted to the special issue, please contact the guest editors at vgalian@uwo.ca (Vicente) or mso693@uowmail.edu.au (Miguel). 